\title{
Vegetation Loss Detection of Nineveh Province Using Remote Sensing Images Based on Ant Colony Algorithm
}

\author{
Younis M. Abbosh ${ }^{1}$, Turkan Ahmed Khaleel ${ }^{2}$, Joanne H. Al-Khalidy ${ }^{1}$ \\ ${ }^{1}$ Comp. \& Info. Engineering Dept. / Electronics Engineering College/ University of Mosul \\ ${ }^{2}$ Computer Engineering Dept. / Engineering College/ University of Mosul
}

\begin{abstract}
Nineveh province in Iraq has experienced a process of land cover conversion and vegetation loss especially in last decades. It is important to get accurate information on vegetation loss and changes in areas that are used for agriculture. Among the most effective methods to study and get information about this phenomenon is remote sensing technology.

Since classical approaches lack of accuracy, artificial intelligence has been introduced to strengthen feature detection which leads to better classification. This paper uses ant colony algorithm to study and classify part of Nineveh province land into six classes. These are Agriculture land/flood plane, Water, Outcrop, Origin of early sand sheet, Desertable area, and Sand dunes. The variation in these six classes from 1987 to 2009 is shown. Results show that agriculture region and flood plain decreased from around $31 \%$ in 1987 to $11.2 \%$ of total area in 2009 while origin of early sand sheet and desertable area increased from $42.7 \%$ to around $49 \%$. Beside that sand dune appears in 2009 to form about $26.47 \%$ of total area under study.
\end{abstract}

Keyword-Remote Sensing, Classification, Ant colony algorithm, Vegetation Loss.

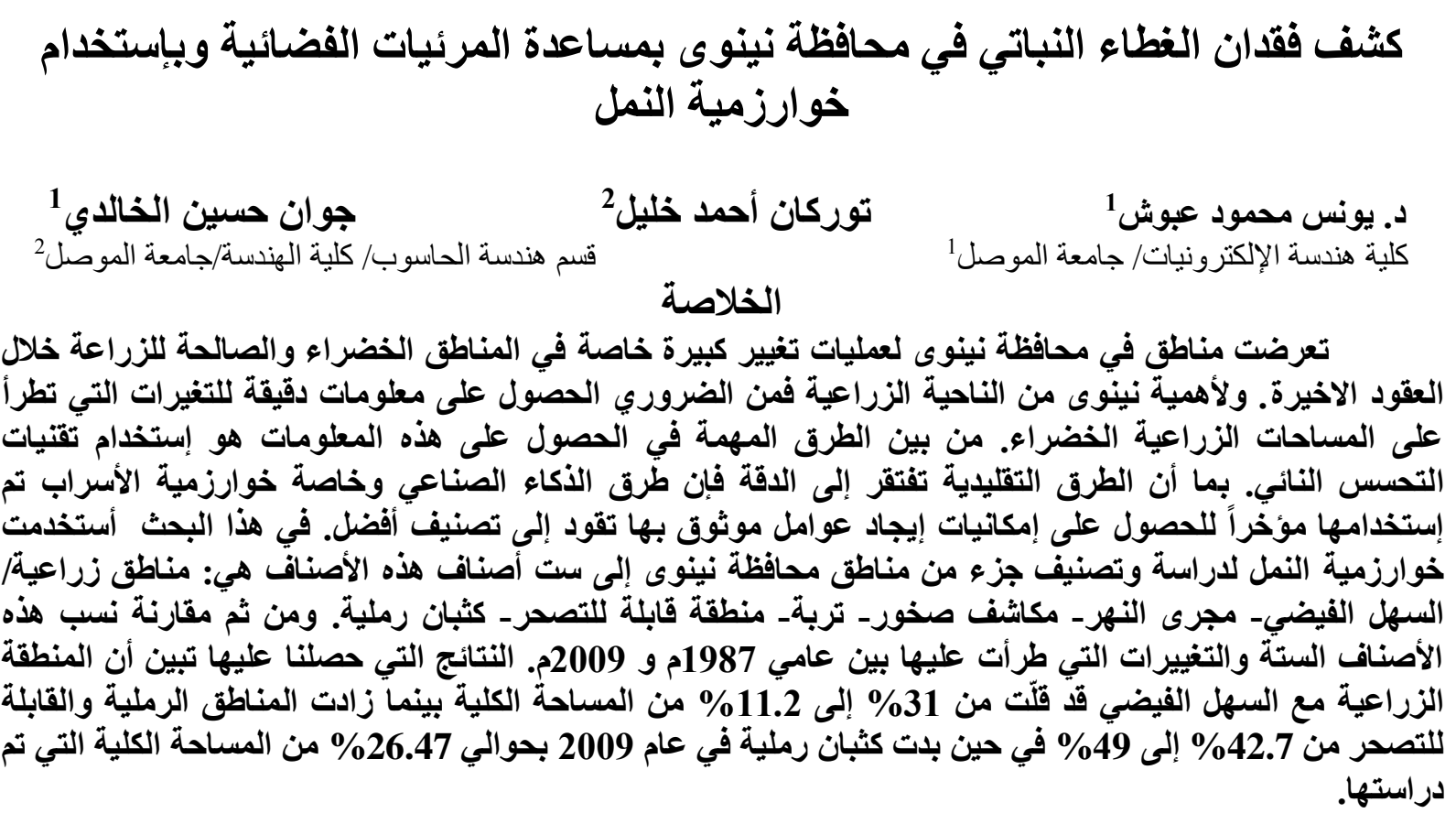

Received: 11 - 10 - 2012

Accepted: 13 - 5 - 2013 


\section{Introduction}

Vegetation loss is one of the most world's problem environmental topics. It is generally driven by a number of factors, alone or in combination, such as variations in climate like wind and shortage of rain and by unsustainable land-management, shifting cultivation practices in dryland environments. Poor soil conservation leads to soil degradation, or when grazing animals eat and remove away grasses and erode topsoil with their hooves. Sometimes an increase in the human population causes of soil degradation. Even political conflicts and war contribute to desertification [1].

For this purpose, many techniques of remote sensing are widely used in vegetation loss detection and classification. The classification of remote sensing image has mainly two ways. One is the visual interpretation and the other is computer automatic classification. The computer automatic classification uses the pattern recognition technology and the artificial intelligence technology [2].

Swarm Intelligence (SI) is a type of artificial intelligence which is among the most techniques that increasingly incorporated in the detection and classification of remote sensing images [3].

Many researches have been done in this field. In 2009, Zhou, Zhang and B. k. proposed a method of feature selection and classification based on ant colony algorithm for hyper spectral remote sensing image [4].

In 2009, Zhang, Huang, and Liu have used Ants to obtain the number of cluster results through intelligent searching the optimum solutions after limited iterations [2].

In 2010, Samadzadegan and Partovi presented a novel feature selection algorithms based on an Ant Colony Optimization (ACO) which is based on the behavior of real ant colonies [5].

This paper presents vegetation loss detection and classification based on Ant colony algorithm and used it for determination of vegetation land and desertification in remote sensing images. It is organized as follows. In section 2 , the study area is introduced. Ant colony algorithm concept is illustrated in section 3 . In section 4, Image classification based on Ant colony clustering algorithm is recognized. In section 5, proposed work is presented and the results are shown in section 6. Finally some conclusions are presented.

\section{Study Area}

Wide regions in Iraq are threatened with vegetation loss that may cause problems in agriculture, human life and activities. One of the threatened areas is Nineveh province. The study area is located in the province of Nineveh situated in the northwestern portion of Iraq

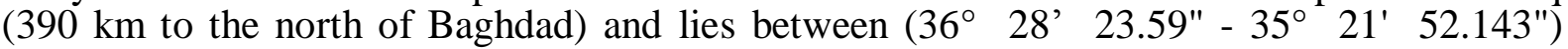
latitude and (41 $\left.54^{\circ} 58.64^{\prime \prime}-43^{\circ} 22^{\prime} 50.65^{\prime \prime}\right)$ longitude as shown in figure (1), which covers an area of about $16,168 \mathrm{~km}^{2}$.

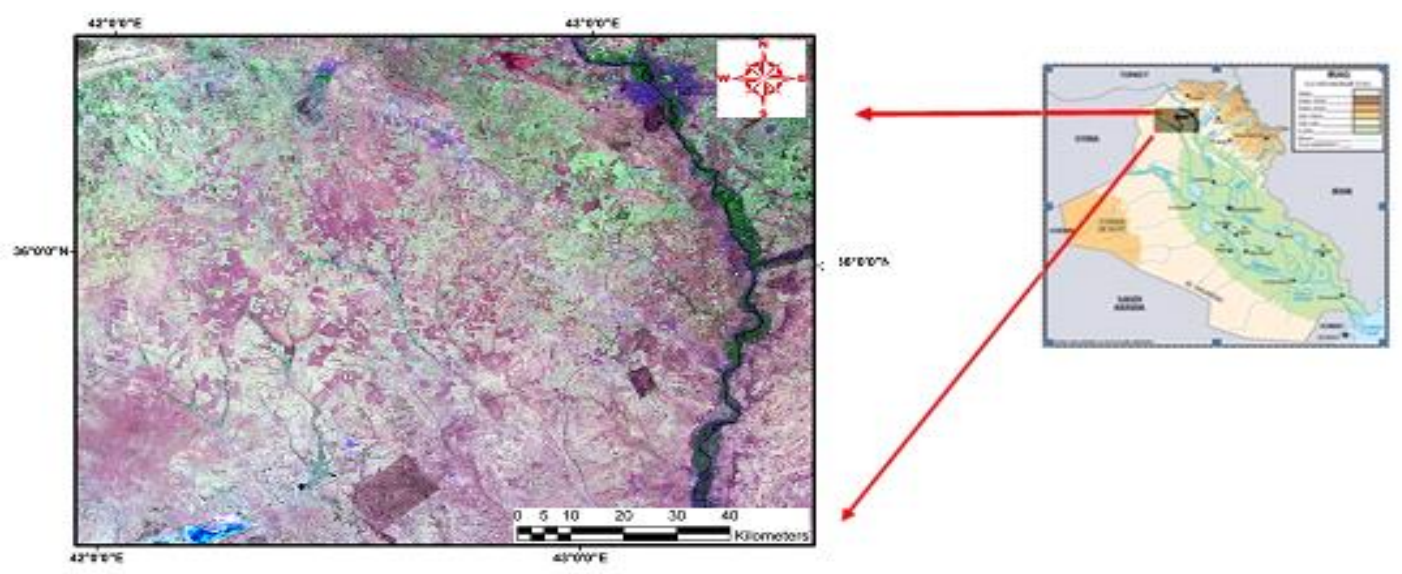

Figure 1: Study area 


\section{Ant Colony Algorithm Concept}

Ant colony optimization is a probabilistic technique for solving computational problems that can be reduced to finding the best paths through graphs. It is a member of swarm intelligence methods that initially proposed by Marco Dorigo in 1992 in his Ph.D. thesis [6][7]. The principle of this algorithm is a cooperative search technique that mimics the forging behavior of real life ant colonies. Although ants are blind, they can always be able to find a shortcut between food sources and their nest by indirect communication with each ant whiles it is walking. A special chemical trail (pheromone) is left on the ground during their trips [2]. This chemical trail guides the other ants towards the target solution by choosing a shortest path, which is called "convergence" in mathematical terms [8]. The more ants pass, stronger pheromone achieves. Furthermore, this will cause higher probability of choosing the path by more ants. An ant will move from node $i$ to node $j$ with probability [9].

$$
p_{i j}^{k}(t)=\frac{\left[\tau_{i j}(t)\right]^{\alpha} *\left[\eta_{i j}\right]^{\beta}}{\sum_{l \in N}\left[\tau_{i l}(t)\right]^{\alpha} *\left[\eta_{i l}\right]^{\beta}}
$$

Where, $N$ is the set of neighboring nodes, $\tau_{i j}$ is the amount of pheromone on edge $i, j . \alpha$ and $\beta$ are important parameters which determine the relative influence of the trail pheromone and the heuristic information. $\eta_{i j}(t)$ is the desirability of edge $i, j$ (typically $1 / d_{i j}$,). After all ants have completed their solutions, pheromone evaporation on all nodes is triggered, and then according to following equation each ant $k$ deposits a quantity of pheromone, $\Delta \tau_{i j}{ }^{k}(t)$ on each node that it has use:

$$
\Delta \tau_{i j}{ }^{k}(t)= \begin{cases}1 / L^{k}(t) & \text { if }(i, j) \in T^{k}(t) \\ 0 & \text { if }(i, j) \notin T^{k}(t)\end{cases}
$$

Where $T^{k}(t)$ is the tour done by ant $k$ iteration $t$, and $L^{k}(t)$ is its length [10][11].

It is clear from Eq. 2 that the value $\Delta \tau_{i j}{ }^{k}(t)$ depends on how well the ant has performed, the shorter the tour done, the greater the amount of pheromone deposited. practically, the addition of new pheromone by ants and pheromone evaporation are implemented by the following rule applied to all the nodes.

$\tau_{i j}(t) \leftarrow(1-p) \tau_{i j}(t)+\Delta \tau_{i j}(t)$

Where $\Delta \tau_{i j}(t)=\sum_{k=1}^{m} \Delta \tau_{i j}{ }^{k}(t), m$ is the number of ants at each iteration and $p \in[0,1]$ represents the evaporation degree of pheromone concentration on path $(i, j)$ after one cycle, and 1- $p$ represents the factor of residual pheromone. The main role of phormone evaporation is to avoid stagnation. All ants can update the phormone according to Eq. 3 and the best ant deposits additional pheromone on nodes of the best solution. This leads to the exploration of ants around the optimal solution in next iteration [5][12]. 


\section{Image Classification Based on Ant colony Clustering Algorithm}

Cluster analysis is a collection of statistical methods, which constitutes a main role of an intelligent data analysis process [13]. In neural network concepts, clustering method is called unsupervised learning because unlike classification (known as supervised learning), no a priori labelling of some patterns is available to use in categorizing others and inferring the cluster structure of the whole data. Main task of clustering is to partition a given data set into groups (clusters) such that the data points in a cluster are more similar to each other than points in different clusters. The similarity of two data vectors is usually based on a (transformed) distance measure, so that we may also say: such that data vectors from the same group are as close to each other as possible and data vectors from different groups are as far away from each other as possible [14].

There are three stages to cluster analysis; namely, partitioning/similarity (what defines the groups), interpretation of clusters (how to use groups), and profiling the characteristics of similar/partitioned groups (what explains the groups). In the first stage, patterns are randomly scattered throughout the grid. Then, each ant randomly chooses a pattern to pick and is placed at a random position on the grid [15]. During the second phase, simple agents perceive the swarm similarity of the current object with the local region, and compute the probability of pick-up and drop. And finally during the third phase, the cluster centres are formed by the simple agents based on collective behaviour [16].

Behaviour of the ant colony shows the positive feedback phenomenon of information. In the ant colony clustering analysis, the provided data are split with separate ants searching for different attributes of cluster centres defined as the "food sources" of ants. Therefore, the process of data clustering can be regarded as the process of foraging ants [17].

\section{Proposed work}

Preprocessing of remote sensing images prior to vegetation loss detection is essential to remove noise and to improve the interpretability or perception of information in images for human viewers, or to provide better input for other image processing techniques. Figure (2) shows the main steps of proposed work.

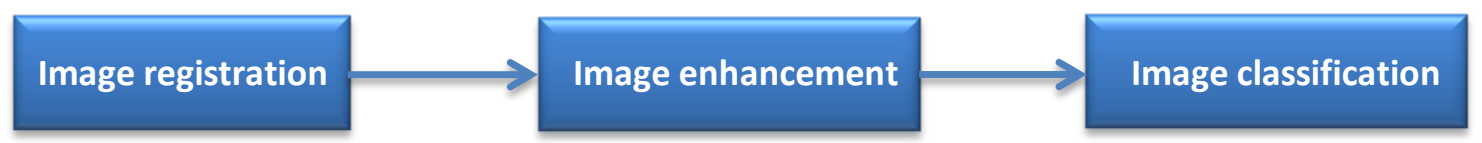

Figure 2: Main steps of proposed work

Two satellite images were selected for present study as shown in figure (3). They were taken by Landsat7 ETM (path/row: 170/35). The first image acquired in 28/4/1987 and the second image was taken in 15/9/2009.

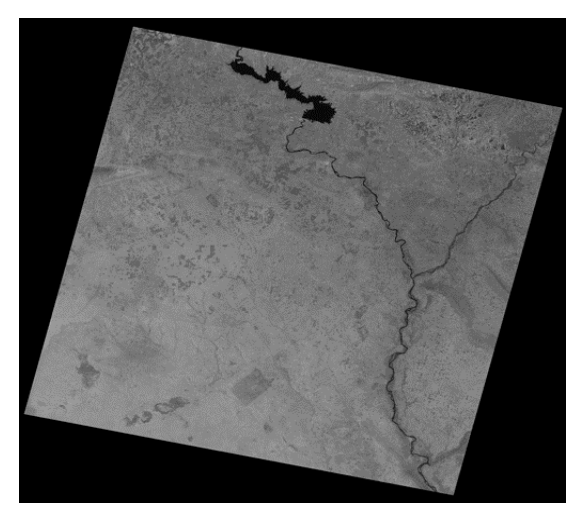

a- Original image in 28/4/1987

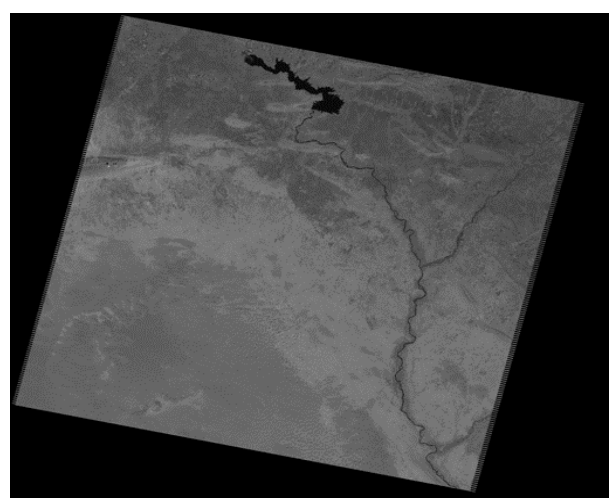

b- Original image in 2009

Figure 3: Original images (Multi dates $(\mathrm{a}, \mathrm{b})$ ) 
After applying the preprocessing steps which include image registration and image enhancement, we got images shown in figure (4). These images represent the area to be studied.

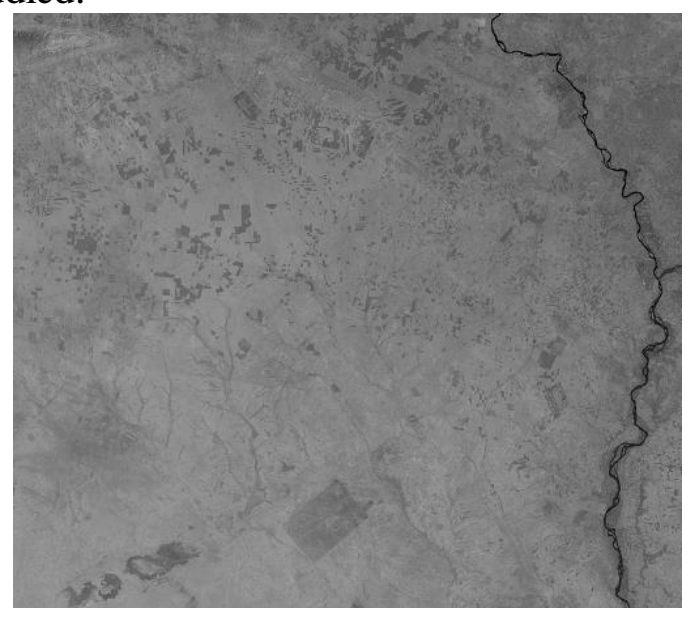

(a)Study region in 1987

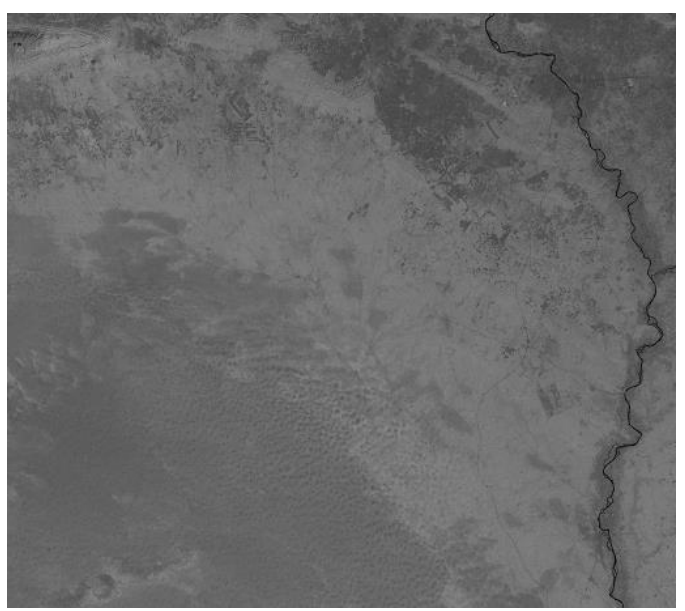

(b) Study region in 2009

Figure (4): Selected area of study region

Based on Ant colony algorithm, the following steps will be performed:

1- $\quad$ Reading remote sensing images and setting them in the program.

2- Enhanced them to improve the interpretability or perception of information in images to provide better input for processing. In this work linear stretch has been used.

3- According to the nature of the area and visual interpretation, six different classes have been chosen including: Agriculture land/flood plain, Water, Outcrop, Origin of early sand sheet, Desertable area, and Sand dunes.

4- $\quad$ Parameters initialization setup, $\alpha=3, \beta=1, \tau_{\mathrm{ij}}(0)=0.8, \mathrm{p}_{0}=0.1, \mathrm{r}=15, \mathrm{~N} \& \mathrm{~m}$ are height and width of image.

5- $\quad$ Assign centre of classes randomly

6- Find the mean which is the average of pixels value in the image by using the equation :-

$M_{i j}=\frac{1}{N X M} \sum_{i=0}^{n} \sum_{j=0}^{m} X_{i j}$

7- $\quad$ Calculate the Euclidean distance between pixels and the average of the image using the equation

$d_{i j}=\left\|p\left(X_{i j}-M_{i j}\right)\right\|$

8- If $d_{i j}$ less than radius $(\mathrm{r})$, then $\tau_{\mathrm{ij}}(\mathrm{t})=1$ else $\tau_{\mathrm{ij}}(\mathrm{t})=0$.

9- $\quad$ Calculating the probability $\mathrm{p}_{\mathrm{ij}}(\mathrm{t})$

10- Judge if $\mathrm{p}_{\mathrm{ij}}(\mathrm{t}) \geq \mathrm{p}_{0}$ then calculate new centre else

11- Calculating Euclidean distance $\mathrm{d}$ from $\mathrm{X}_{\mathrm{i}}$ to all cluster centres and find the minimum.

12- Classifying the image and assigned to each category.

13- Repeating steps from 7-12 until there is no modification in class centre vector.

14- Output the image (classification result). 
The general structure of flowchart used for image classification based on ant colony is depicted in the figure (5).

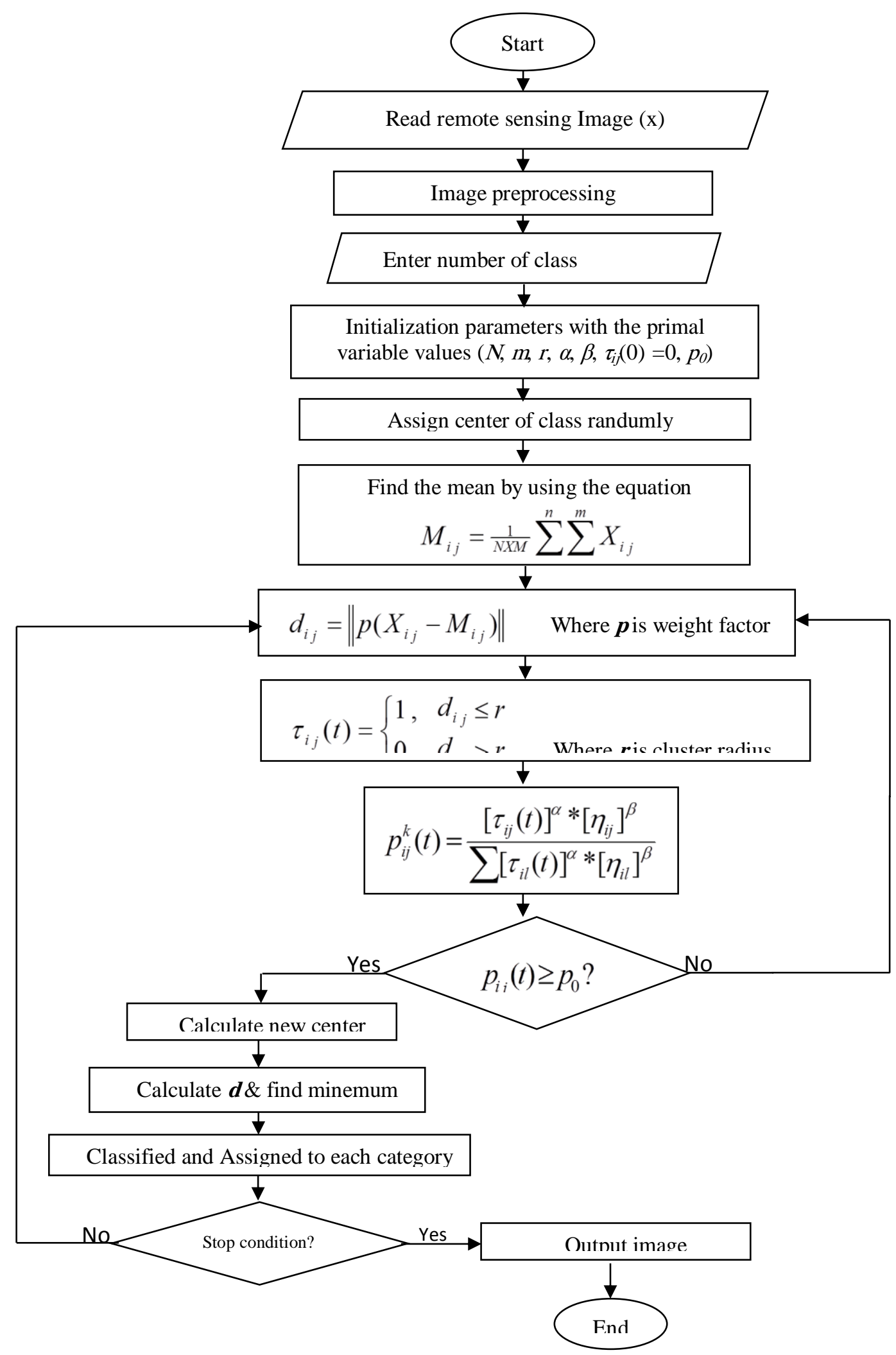

Figure 5 : Flow chart of image classification used in this study 
In this work, the remote sensing image classification was employed depending on the Ant colony clustering. An integrated program has been designed to perform the equations (1), (2), (3), (4) and (5) by using Microsoft Visual C++ 6.0 which works under the system of windows.

\section{Results}

As can be observed from figure (6), the clustering based on ant colony algorithm could clearly detect land cover types from remote sensing image. And according to that classification has been conducted. The interpretation of each class in the digital classification for the satellite images date (1987) has been made depending on the map of Al-Daghastani as shown in figure (7) [18].

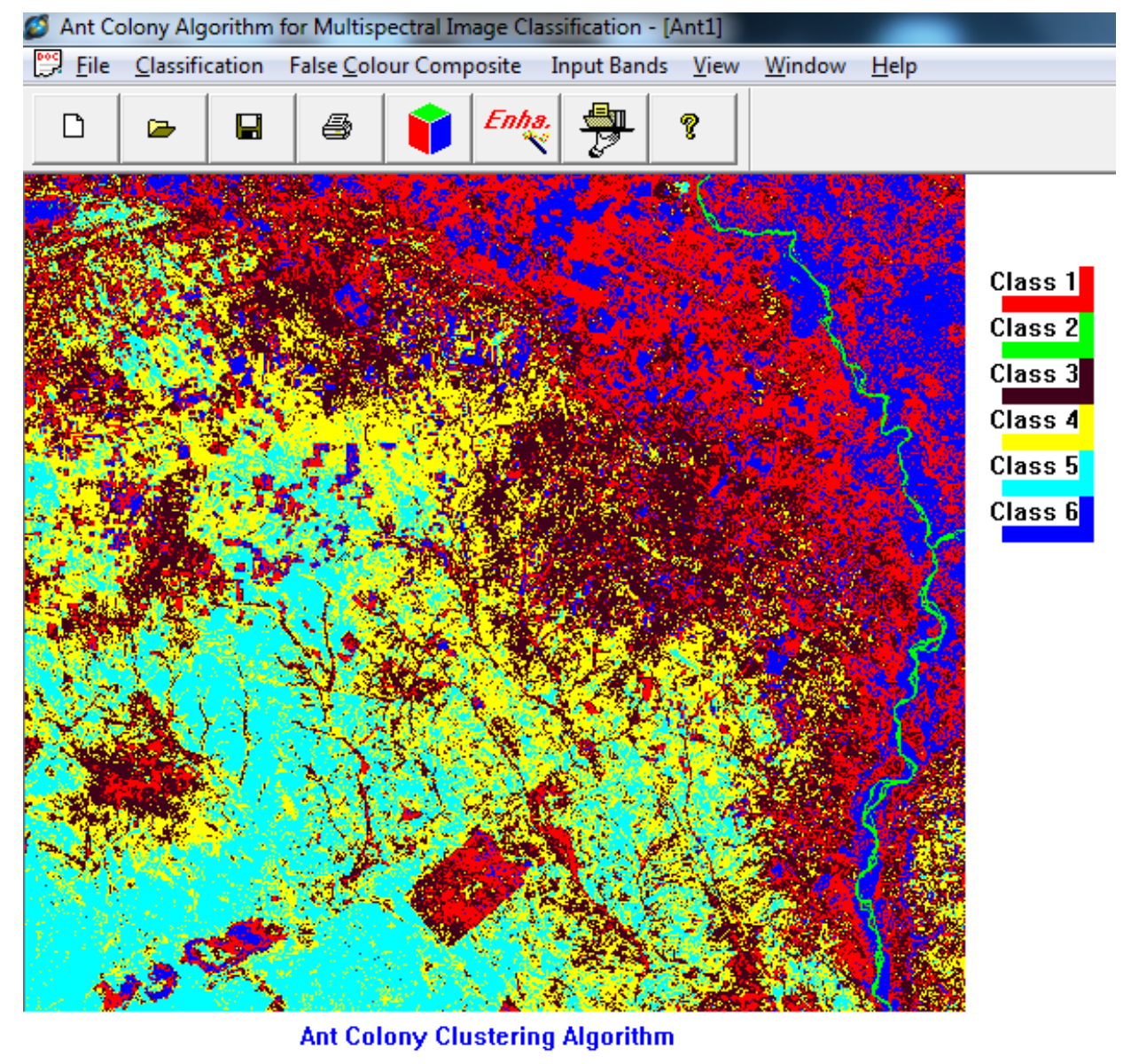

Figure 6: Study region in 1987 


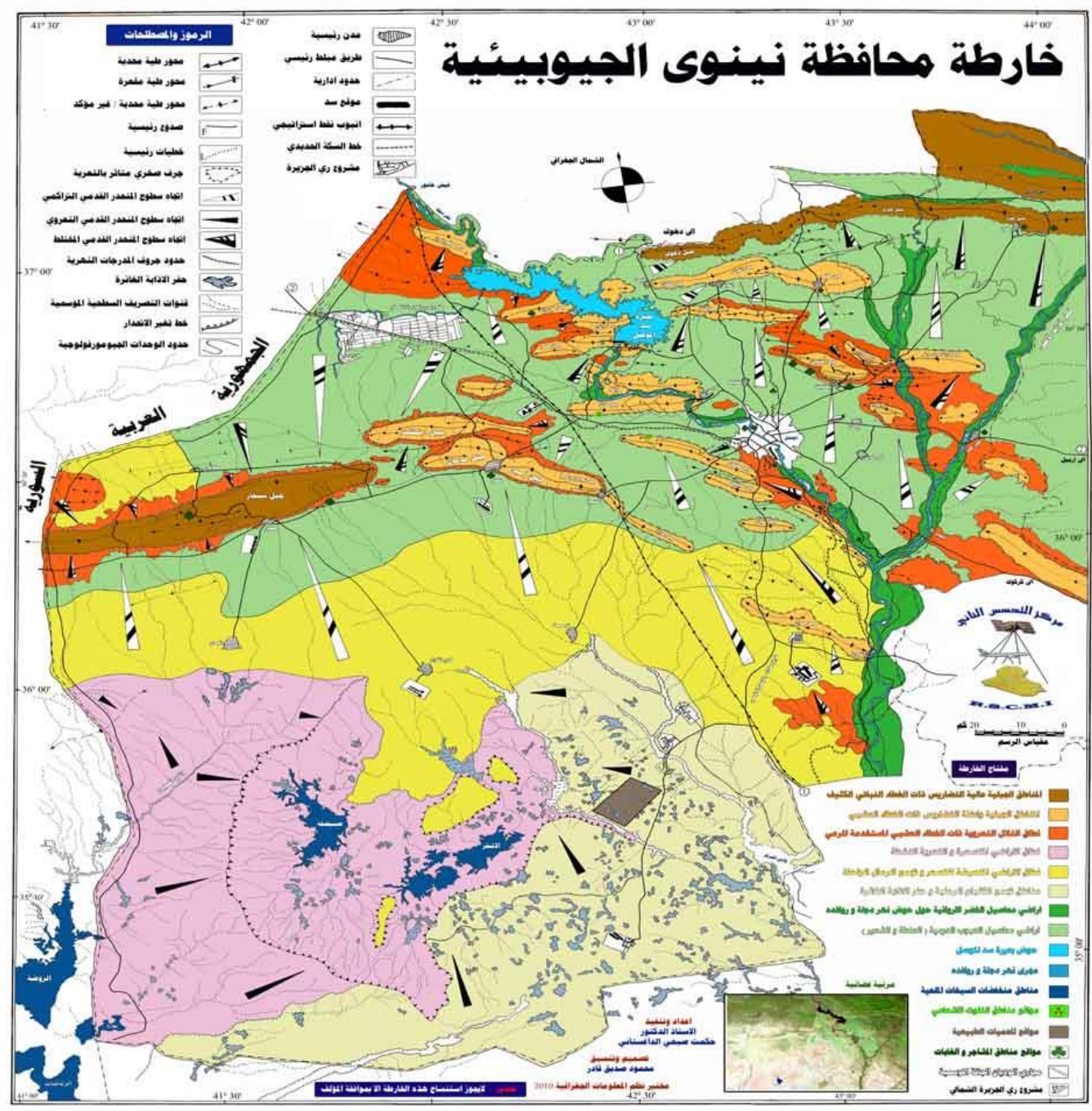

Figure (7): Geo-environmental classification map of Nineveh governorate using remote sensing data (Al-Daghastani, 2010).

On the other hand, there is another interpretation for the satellite images dated (2009) depending on the other map of Al-Daghastani shown in figure (9)[19] 


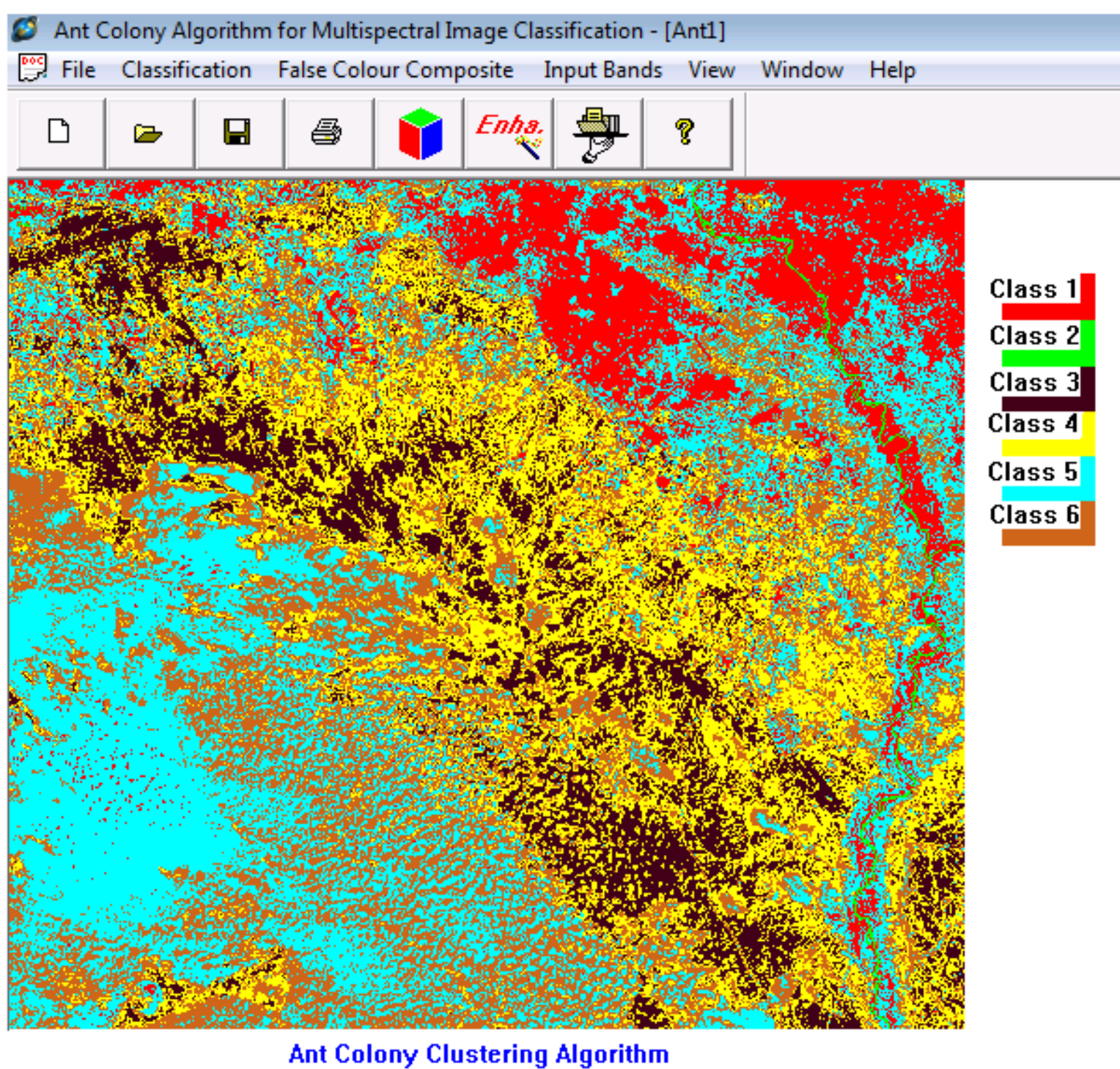

Figure 8: Study region in 2009 "after processing “ 


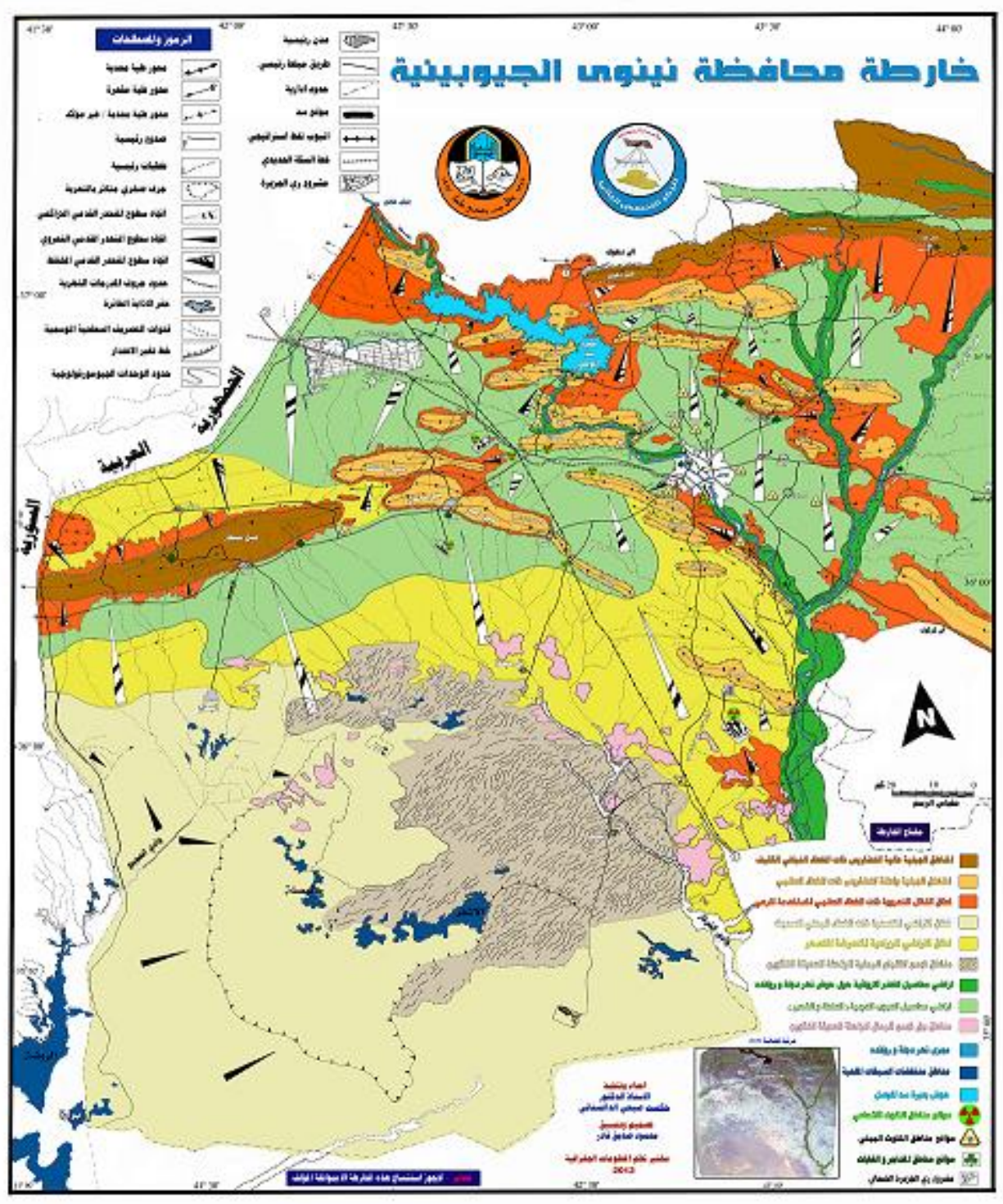

Figure 9: Geo-environmental classification map of the Nineveh Governorate using remote sensing data (Al-Daghastani, 2013)

Table 1 and 2 show the percentage of each class of total area studied.

Table 1: Percentage of each class using Ant colony

\begin{tabular}{|c|c|c|}
\hline & Colour & Year 1987 \\
\hline Class 1 & Red (Agriculture land) & $19.429 \%$ \\
\hline Class 2 & Green (Water) & $0.593 \%$ \\
\hline Class 3 & Black (Outcrop) & $25.659 \%$ \\
\hline Class 4 & $\begin{array}{c}\text { Yellow (Origin of early } \\
\text { sand sheet) }\end{array}$ & $24.777 \%$ \\
\hline Class 5 & Cyan (Desertable area) & $17.928 \%$ \\
\hline Class 6 & Blue (Flood Plain) & $11.611 \%$ \\
\hline
\end{tabular}


Table 2: Percentage of each class using Ant colony

\begin{tabular}{|c|c|c|}
\hline Class 1 & $\begin{array}{c}\text { Colour } \\
\text { Agriculture land) } \\
\text { Agriood Plain and }\end{array}$ & Year 2009 \\
\hline Class 2 & Green (Water) & $0.398 \%$ \\
\hline Class 3 & Black (Outcrop) & $12.973 \%$ \\
\hline Class 4 & $\begin{array}{c}\text { Yellow (Origin of early } \\
\text { sand sheet) }\end{array}$ & $21.152 \%$ \\
\hline Class 5 & Cyan (Desertable area) & $27.783 \%$ \\
\hline Class 6 & Brown(Sand Dunes) & $26.474 \%$ \\
\hline
\end{tabular}

Results shown in tables 1 and 2 indicates that agriculture land and flood plain decreased from about $31 \%$ in 1987 to $11.2 \%$ in 2009 of total area whilst origin of early sand sheet and desertable area increased from $42.7 \%$ to nearly $49 \%$. And finally we realized that sand dune become clear in 2009 to be about $26.47 \%$.

\section{Conclusions}

From results it can be noticed that Ant-based clustering algorithms are an appropriate alternative to traditional clustering algorithms as it has rapid convergence. It can be seen that the proposed method has classified the image into 6 classes as mentioned in results previously. The results show that in study area of Nineveh province agriculture land and flood plain decreased by about $20 \%$ of total area while origin of early sand sheet and desertable area increased by more than $6 \%$. Furthermore, sand dune seems to form around $26.47 \%$ of total area studied.

\section{References}

[1] Desertification, 2010. A Report Of The Millennium Ecosystem Assessment, International Fund For Agricultural Development Via Paolo Di Dono, 4400142 Rome, Italy, Available at: http://www.ifad.org/pub/factsheet/desert/e.pdf.

[2] Zhang, H., Huang, F., Guo, J. and Liu., M., 2009. Automatic Classification of Remote Sensing Image Using Ant Colony Clustering Algorithm. School of Urban and Environmental Sciences, Changchun, China, IEEE 978-1-4244-4131-0/09.

[3] Xie, Y., Li, L., Wang, H. and Zhao, X., 2010. The Application of Threshold Methods for Image Segmentation in Oasis Vegetation Extraction, 18th International Conference on Geoinformatics, Provider: IEEE Publisher: IEEE DOI: 10.1109/GEOINFORMATICS, pp. 1-4.

[4] Zhou, S., Zhang, J.P. Su, B.K., 2009. Feature Selection and Classification Based on Ant colony Algorithm for Hyper Spectral Remote Sensing Images. Institute of Technology Harbin, China, IEEE 978-1-4244-4131-0/09.

[5] Samadzadegan, F. and Partovi, T. 2010. Feature Selection Based on Ant Colony Algorithm for Hyperspectral Remote Sensing Images, Reykjavik, Iceland, IEEE 9781-4244-8907-7/10, pp.1-4.

[6] Colorni, A., Dorigo, M. and Maniezzo, V., 1991. Distributed Optimization by Ant Colonies, Appeared In Proceedings Of Ecal91 - European Conference On Artificial Life, Paris, France, Elsevier Publishing, pp. 134-142. 
[7] Dorigo, M., 1992. Optimization, Learning and Natural Algorithms, Ph.D. thesis, Politecnico di Milano, Italie.

[8] Ostfeld, A., 2011. Ant Colony Optimization Methods And Applications. Published by InTech Janeza Trdine 9, ISBN 978-953-307-157-2.

[9] Rao, S. S., 2009. Engineering Optimization Theory and Practice, Fourth Edition, John Wiley \& Sons, Hoboken, New Jersey.

[10] Machnik, L., 2006. Documents Clustering Method Based in Ants Algorithms, Proceedings of The International Muticonference on Computer Scince and Information Technology, ISSN 1896-7094, pp. 123-130.

[11] Abarghouei, A. A., Ghanizadeh, A. and Shamsuddin, S. M., 2009. Advances of Soft Computing Methods in Edge Detection, Int. J. Advance. Soft Comput. Appl., Vol. 1, No.2, ISSN 2074-8523.

[12] Aghdam, M. H., Aghaee, N. G. and Basiri, M. E., 2009. Text Feature Selection Ant Colony Optimization, Elsevier Science, pp. 6843-685.

[13] Jafar, O. A. M. and Sivakumar R., 2010. Ant-based Clustering Algorithms: A Brief Survey, International Journal of Computer Theory and Engineering, Vol. 2, No. 5, pp. 1793-8201.

[14] Borgelt, C., 2005. Prototype-Based Classification and Clustering, Ph.D. thesis, GuerickeUniversity, Magdeburg, pp. 1-341.

[15] Villwock, R., 2011. Pattern Clustering Using Ants Colony, Ward Method And Kohonen Maps, International Conference on Evolutionary Computation Theory and Applications(ECTA), pp. 137-145.

[16] Sumathi, S. and Paneerselvam S., 2010. Computational Intelligence Paradigms, Theory And Applications Using MATLAB. first Edition, Taylor and Francis Group, LLC.

[17] Chircop, J. and Buckingham, C. D., 2011. A Multiple Pheromone Algorithm for Cluster Analysis, International Conference on Swarm Intelligence (ICSI), Cergy, France, pp. $1-10$.

[18] Al-Daghastani, H. S., 2010. Geo- environmental map of Nineveh Governorate. Remote Sensing Center. (1'st edition).

[19] Al-Daghastani, H. S., 2013. Geo- environmental map of Nineveh Governorate. Remote Sensing Center. (2nd edition). 